\title{
THE IMMIGRANT EXPERIENCE IN JONAS MEKAS'S DIARY FILMS: A CHRONOTOPIC ANALYSIS OF LOST, LOST, LOST
}

\author{
EFRÉN CUEVAS
}

Jonas Mekas, who emigrated from Lithuania to the United States in 1949, became a leading figure in the American independent cinema and a prominent film diarist, helping to establish this practice as a legitimate audiovisual form. In this article, I examine his immigrant experience through a close analysis of his film Lost, Lost, Lost (1976), ${ }^{1}$ where he deals with this issue thoroughly. This film constitutes a singular case within cinematic immigrant autobiography, not only because it records a diary, a genre scarcely cultivated in cinema, but also because most of the attempts to portray the immigrant experience autobiographically in film have been done by second and third generation immigrants.

In my analysis I look first at Mekas's diary film practice. Then I explore the narrative of his American immigrant experience as reflected in Lost, Lost, Lost, helped by the chronotopic approach to literary analysis proposed by Mikhail Bakhtin, an approach that has been used in cinema studies by scholars such as Michael V. Montgomery and Vivian Sobchack, though never with film diaries. ${ }^{2}$ I intend to show that Bakhtin's proposals provide a valuable approach to the analysis of immigrant autobiographies in cinema, since the film medium is so tied to the experience of time and space-both so crucial in the configuration of the immigrant identity in the new country.

\section{MEKAS'S WORK: FROM FILM DIARIES TO DIARY FILMS}

Mekas's diary films are clearly grounded in autobiographical practice, a frontier area where fiction and non-fiction conflate. This mixed character gives to autobiography a paradoxical nature, as Dario Villanueva explains: it is fiction from a genetic point of view, since the author does not pretend to reproduce 
reality, but to create his/her own self; however, it is also "reality" or "truth," and it is understood as such by the reader/spectator, who makes an intentionally realistic reading/viewing (28). Following Paul John Eakin, this mixing of fiction and non-fiction can also be approached by placing autobiography within the broader practice of self-narration, with "narrative identity" as the key concept unifying both practices. Eakin underlines that "narrative is not merely a literary form but a mode of phenomenological and cognitive self-experience." That is why he argues that "to speak of narrative identity is to conceptualize narrative as not merely about identity but rather in some profound way a constituent part of identity, specifically of the extended self that is expressed in self-narrations" ("Breaking" 115). From this point of view, autobiographical films like Mekas's can be seen as sharing a basic ground with standard fiction films in their common exploration of personal identity in narrative terms.

Mekas's diaries also can be placed in another frontier more related to the film medium, in the netherworld between experimental cinema and documentaries. The unequivocal indexical dimension of the filmic images of the diaries is counterbalanced by the strong subjectivity of his films, placing them in a middle ground between two practices-experimental and documentary -once antagonistic, though nowadays increasingly linked. ${ }^{3}$ This is due to the evolution during the last decades of the documentary practice, which has amplified its conventional focus on the historical world to include more personal approaches. These changes have led to the increasing presence of autobiographical works, among them what Jim Lane calls the "journal entry," which he defines as "a type of autobiographical documentary that involves the shooting of everyday events for a sustained period of time and the subsequent editing of these events into a chronological autobiographical narrative" (33). ${ }^{4}$ This approach has been employed by a number of filmmakers in the last few decades, including Ed Pincus, Ross McElwee, and Marco Williams, who resort to a composition similar to the standard dramatic structure of fiction films, evolving around a personal crisis, with closure marked by its solution. Other filmmakers such as Johan van der Keuken and David Perlov, work with a more literal diarist approach, with no evident conflict or closure in the structuring of their personal accounts. Mekas is probably one of the best representatives of the second approach, consistently filming and editing movies that record his daily activities for more than fifty years. As such, Mekas's work offers an impressive perspective on the strengths and weaknesses of the diary format in cinema.

The process of making diaries in film or video is both similar to and different from writing a diary. They share the two basic generic features pointed 
out by Jean Rousset: secrecy (in the sense of privacy) and regularity (158). However, audiovisual diaries are distinguished from written diaries most notably by their double temporality, as David E. James shows when he proposes a double naming to describe more accurately the whole process. ${ }^{5} \mathrm{~A}$ first term, "film diary," would refer to the daily images and sounds filmed throughout the years. This would suggest a close connection with the standard written diary, though with no temporal distance between the event and its diary entrance. It is a private moment, when the only spectator is the author, and perhaps later on, his/her close family, with no public exhibition intended. When the author/filmmaker decides to make a "film" out of the filmed diaries, s/he then creates a "diary film," transforming private records into public discourse and expanding their original meaning. At this point, James notes, the film diary's reach is "extended into a mode of greater discursivity, one capable of social extension and of dealing with the past" (161).

This double temporality points towards other peculiarities that manifest themselves when we study the process of construction. In the first place, the shooting of the image provides an eternal "present" time, with an immediacy not achievable in written texts. The camera captures the instant of the people performing their daily routines. At the same time, both the characters and the filmmaker openly acknowledge the process of filmmaking as part of their lives, introducing a complex interplay between the factuality of the recordings and its performative dimension. The film diarist openly shows that process, resorting to practices inspired by the home-movie approach. This is especially true in Mekas's work. His diary films have an amateur quality, with the supposed defects of home movies now becoming a mark of style, a rejection of the standardized practices of industrial cinema. Mekas's works-and that of the other diarists - acquire added meanings, since they present their films as acts of vindication of a new cinema, removing them from the private domain to turn them into public statements. ${ }^{6}$ The subjective dimension of these works is also reflected in the highly self-conscious molding of the film, making them function, as Susanna Egan states, "as an extension of the body, as a source of experience rather than design" (97). ${ }^{7}$ For Jonas Mekas, the main challenge when filming a diary becomes "how to react with the camera right now, as it's happening; how to react to it in such a way that the footage would reflect what I feel that very moment" ("Diary" 191). To achieve this, Mekas needs to transcend standard styles, appropriating modes of the avantgarde: "I had to liberate the camera from the tripod, and to embrace all the subjective film-making techniques and procedures," to manage therefore "to merge myself with the reality I was filming, to put myself into it indirectly, by means of pacing, lighting, exposures and movement" ("Diary" 192). 
The second stage in the construction of the diaries-the editing-actually takes place in two phases: the present time, when the filmmaker is editing during the shooting, "structuring the work," as Mekas says, as it is being made; ${ }^{8}$ and the posterior time of the standard editing, when the different scenes are put together. That second editing is more relevant to the final product, because the film cannot be as long as a written diary. Nevertheless, in Mekas's diaries, those editing choices are mainly related to the span of time included, keeping the chronological and fragmented structure akin to the written diary, and respecting the in-camera editing so crucial in his films. In fact, he refers to that "second" process of editing as simply "elimination, cutting out the parts that didn't work, the badly 'written' parts" ("Diary" 193).

In that final editing, Mekas adds several layers of sounds and texts, which enhance the subjectivity and creativity of the work. He introduces descriptive, symbolic, or poetic titles to punctuate the general structure of the film, and adds sounds-from street noise to music to human voices-for effect. His voice-over commentary is the most important later addition, explicitly foregrounding the double temporality of these diaries, transforming the present of the shooting into the past of the remembering. As Maureen Turim explains, "the cinematographic rendering of moments considered present at the instants of their recording become memoirs when recollected through montage, a montage that includes a voice situating the emotions of the time. The voice carries the weight of pastness. It turns the phenomenology of experience into that of reminiscence" (209). This voice-over brings in a highly reflexive dimension to the film, moving it away from an explicit diaristic format towards a more standard autobiographical work, since it introduces the retrospective perspective of the narrative that is absent in diaries. ${ }^{9}$ The outcome offers a singular balance between a diary and an autobiography: the visual track refers strongly to the diary format, with the daily shooting providing the typical entries of a diary; but the final editing and the voice-over compose the visual entries into a certain narrative, giving a closure to the images, or following Turim, converting them into memoirs.

This complex presentation of Mekas's diary films is especially evident in Lost, Lost, Lost, where there is a structuring of the images into a peculiar narrative of Americanization, as we will see in the following pages. This structuring is very visible because of Mekas's division of the film into six reels. The change of reel, marked by written titles, also introduces changes of mood and topic, charting the evolution of Jonas Mekas as an immigrant in his new country. Therefore, Lost, Lost, Lost offers a singular mixing of formats and modes, from diary to autobiography, from the non-fiction mode of homemovie making to the personal narrative of the immigrant quest. 


\section{LOST, LOST, LOST: A CHRONOTOPIC ANALYSIS OF MEKAS'S EXPERIENCE OF DISPLACEMENT}

Because Mekas began filming soon after his arrival in the United States, his early footage registered his experience as an immigrant in the New York of the fifties, as well as his progressive adaptation to the new country. That footage was shown first at the beginning of his 1972 film Reminiscences of a Journey to Lithuania, ${ }^{10}$ and in more detail in Lost, Lost, Lost, a film made out of footage shot from 1949 to 1963, but edited in the mid-seventies and released in 1976. This later film constitutes a unique blend of perceptions of the immigrant experience and film autobiography, because the filmmaker is a first-generation immigrant dealing with his own experience through a diary format that poses its own challenges for providing a narrative of that experience. ${ }^{11}$

The main quality that Lost, Lost, Lost establishes from the beginning is related to the temporal framework of the film. This begins in 1949, making Lithuania the primary absent protagonist. Mekas's reflections center therefore on the process of acculturation in America- a feature common to most film diaries, given the inherent constraints of the medium. The testimonial dimension of the image leaves the filmmaker without the possibility of recording his childhood and youth. ${ }^{12}$ Besides, since Mekas is an immigrant, there is a second obstacle to the recording of that first period of his life. The material conditions of production-the dependence upon filmic apparatus, plus the industrial framework required-make it improbable to find this kind of personal shooting during the time lived in his native country. These material constraints offer a specific approach to immigrant autobiography in cinema that bypasses or reviews quickly the first two stages pointed to by William Boelhower as characteristic of immigrant autobiography - the dream anticipation and the journey (Immigrant 28-40) — to focus instead on the process of acculturation to the new country.

Mikhail Bakhtin's chronotopic analysis of literature can help us understand this process. Bakhtin proposed focusing on the study of chronotopes, singular combinations of time and space in each work of art where narrative events become specific: "It is precisely the chronotope that provides the ground essential for the showing-forth, the representability of events. And this is so thanks precisely to the special increase in density and concreteness of time markers - the time of human life, of historical time - that occurs within welldelineated spatial areas" (250). As Sobchack points out, for Bakhtin these chronotopes were not a mere backdrop to the plot, but "they provide the literal and concrete ground from which narrative and character emerge as the temporalization of human action, significant in its diacritical marking of both 
cultural and narrative space" (151). They therefore provide specific markers for the development of the story, limit its narrative variations, shape characterization, and provide the most significant axiological sites of the work.

Transposing Bakhtin's approach from novel to film seems natural, given the spatial and temporal materiality of the film medium. The film is shot and projected in time, and it projects a space on the screen that represents the physical space of the shooting, either constructed for fiction films or representing the empirical world in documentaries. ${ }^{13}$ This is especially evident when working with diary films, since the filmmaker is working necessarily with images placed in temporal frames to disclose his worldview. The chronotopic approach can also be especially fruitful in the study of immigrant autobiographies, since it foregrounds the temporal and spatial experience so crucial in immigrant lives. As Betty Bergland explains, "reading autobiographies chronotopically, especially those of the cultural Other, permits us to read differently - to apprehend the effect of discourses in which the autobiographer is situated by examining the subject's temporal and spatial placement in the world" (156).

Those effects are even more visible when focusing specifically on the spatial experience, contrasting the places left behind with their new location. "[H]abitare," Boelhower explains, "is an essential property of existence and as such is also the foundational dynamic behind the montage conventions of autobiography" (Autobiographical 29). Boelhower is actually talking about the crisis of habitare visible in modernist autobiographers, who turn their focus from the temporal structure typical of the genre to a spatial understanding, a quest for dwelling where the modern city is anathematized and the historic city mythologized. But his remarks can be translated to transcultural autobiographies, since the immigrant experience can be explained as a quest for dwelling, a struggle to fit into the modern city of an alien country, in sharp contrast with the idealized place left behind.

That centrality of space becomes manifest in Lost, Lost, Lost due to the interplay between the diary format and the immigrant experience. On the one hand, Mekas's experience of his new country is clearly marked by the places where he lives in New York: first in the Brooklyn neighborhood of Williamsburg, and later on in Manhattan. On the other hand, the structure of his film makes the temporal dimension lose its momentum, since the chain of events represented is not tied to a closed causal structure, but rather is based on his daily shooting of the normal events around him. The film's temporality therefore comes rather close to the "cyclical everyday time" described by Bakhtin, where "there are no events, only 'doings' that constantly repeat themselves" (247), as happens precisely in standard home movies. 
The prominence of the spatial experience does not mean that the temporal dimension is irrelevant in Mekas's films. The films' double temporalitythe distance between the filming and the final editing - produces a suggestive discourse that links the spatial experience to the temporal axis, mainly through the voice-over commentaries. At the same time, this interplay between the voice-over and the images helps to foreground the different roles that Mekas takes on during Lost, Lost, Lost, as narrator and protagonist. His position as narrator becomes dominant through the use of the voice-over, though it is evident too in the writing of the titles. At the same time, he is the protagonist of the events, a presence felt through his elaborate and self-conscious shooting and editing, which call attention to himself as the filmmaker watching, recording, and reacting to events. This presence goes farther, to the point of becoming literally visible when other people film him-his brother Adolfas, but also Ken Jacobs in reel six. Those two roles, narrator and protagonist, acquire new meanings when Mekas puts them in dialogue and in relation to the places and times that define the main chronotopes. Through this interplay, Mekas appears as a wanderer, watcher, or guardian of the new cinema, depending on the place and time where he locates himself. In this way his film becomes what Bergland, paraphrasing Michael Fischer's work on ethnic autobiographies, describes as a "meaningful site for exploring multiple subjectivities with implications for the larger culture" (134).

\section{MEKAS THE WANDERER/WATCHER: THE STREET AS CHRONOTOPE}

Lost, Lost, Lost can be divided into three blocks of two reels each. The first block deals mainly with the life of the Lithuanian immigrant community and Mekas's situation as a displaced person. He locates himself within this community, feeling its displacement keenly, missing his home, his family, and the time spent with them. Nevertheless, right from the beginning he works toward creating a new world for himself through his writing and filming. He had kept a written diary since 1944, seen in parts of reel one, where he also reads portions of it in a voice-over. ${ }^{14}$ More strikingly, he also decides to film daily routines of his new life, embracing the camera as a means of personal expression-exploring, as Egan has said about other autobiographical filmmakers, "subjective expression by means of the technology that has come closest to suggesting objective realities" (97). Mekas's double diary practice gives him a special consciousness toward his experience as an immigrant, creating a distance that was physically realized by filming the events surrounding him.

In these first reels, Mekas's experience of displacement is materialized through the chronotope of the street, since this place works, paraphrasing 
Bakhtin's formulation, as the essential ground for the representability of Mekas's struggle during his first years in America. The street functions here similarly to the chronotope of the road described by Bakhtin in his work, since it shares some of its qualities as a place of random encounters, of collision and interweaving for different groups and social classes (243-45). But the street of these first reels lacks any direction, becoming more a place where people may stay or pass through but where no one establishes a home. It is a place with no owner, where no roots can grow, where one is surrounded by multitudes, though one can in fact be alone. The street also represents other open urban spaces in these first reels: the park, the square, and so on. This resort to public open spaces could be explained partially by the routines of home-movie making, so often linked to shooting on special occasions, usually related to "going out." But in Lost, Lost, Lost the street acquires a deeper meaning, as the place where Jonas Mekas feels most attuned to his life as a displaced person. He aimlessly wanders the streets of New York, feeling deep inside the loneliness of his displacement as immigrant.

That idea is explicit in reel one, where he is seen walking alone on the streets, while two titles say: "THRU THE STREETS OF BROOKLYN I WALKED," followed by "I WALKED MY HEART CRYING FROM LONELINESS." 15 Just after those titles, and over images of different public spaces of New York, his voice-over underlines the same idea: "Those were long, lonely evenings, long, lonely nights. There was a lot of walking, walking, through the nights of Manhattan. I don't think I have ever been as lonely." Mekas resorts to the streets as a way to avoid that loneliness, as he says when commenting on the images of Ginkus at the front of his candy store: "We couldn't sit home. It was too lonely. The streets were empty. We stopped at Ginkus's candy store." Mekas here is creating a representation of loneliness by mixing literal and symbolic figures through the image and sound track. The voice-over mixes the denotative description of some of the images with the poetic strand of other sentences. The image also becomes symbolic when he himself is seen on the screen, since that loneliness is no longer literal, because someone-probably his brother Adolfas—was filming him. The image of Mekas walking alone on the streets becomes therefore a representation of his inner state, where displacement and homesickness dominate.

Mekas also explores this displacement in explicitly political terms. As we hear in the voice-over and see implicitly in the images of the life of the Lithuanian community during the first two reels, he sees himself as a forced immigrant. In fact, the beginning of reel one starts with that issue in voice-over, when Mekas asks Ulysses to sing the story of "a man who never wanted to leave his home, who was happy and lived among the people he knew and 
spoke their language. Sing, how then he was thrown out into the world." The figure of Ulysses reappears in reel two, as Mekas twice calls upon him to protect Lithuania. Ulysses therefore serves as an alter ego for Mekas, a symbol of the displaced person who comes from a country rich in tradition and culture. ${ }^{16}$ That feeling of displacement, of being "thrown out" of his country, grows during the first years of his life in New York as shown in these reels, and is intensified by the contrast between that Lithuania recreated by the immigrants and his growing perception of the impossibility of recovering his country and his home. This contrast takes on a sad irony through the juxtaposition of happy images of social gatherings (weddings, dances, picnics in the parks) and the melancholic remembrance of those times in the voice-over. The figure of the wanderer, evoked by the first images of him walking on the street, is now echoed in images of people sitting in the streets with no apparent purpose-those old Lithuanians that he films in reel one "WITH NO MEMORIES," as he comments in the title.

Reel two introduces a slight change of mood. Here Mekas becomes a chronicler of the political and social life of the Lithuanian community in New York. He takes the role of a privileged watcher, filming their gatherings, their protests, picket lines, and meetings. The street as chronotope acquires a more overt political content, with Mekas as the reporter of the Lithuanian minority. As he says in the voice-over, he is there as "the chronicler, the diarist," or "the camera eye ... the witness." His gaze remains rather distant, though sometimes his voice-over remembers those images with emotion, as when he asks: "Oh, let my camera record the desperations of the small countries." Nevertheless, this distance helps him progressively to perceive that the political aspirations of the Lithuanian community are unreal.

Because of this realization, and because he "had been turning on one spot, around my memories," Mekas resolves to move away from that setting. Deciding to build himself up from scratch, as he says again in the voice-over, he breaks with his life in Williamsburg, and moves to Manhattan. Here again, the spatial understanding of the self is foregrounded. Since he understands that there is no point in trying to live off past memories, as if he was on the verge of returning, and since that kind of life was embodied by the neighborhood of Williamsburg, to begin from scratch meant having to move away into a new exile ("I felt I was falling to one thousand pieces," he says). Though his new home was quite close, the distance was more symbolic than physical, since it meant acknowledging the impossibility of recovering his homeland.

A change of reel clearly marks this change to his new place. Reel three begins with Jonas and Adolfas living in Manhattan, involved in the life of independent filmmaking-launching the Film Culture magazine, shooting 
different films, or spending time with film critics like Peter Bogdanovichand in other cultural events, such as a gathering of poets at the Living Theater, with Ginsberg, Bremser, and LeRoy Jones. We witness Mekas's process of Americanization, but this process is quite atypical, since his point of view always remains rather critical of mainstream American values. Mekas's diaries therefore depart from the standard pattern of written immigrant autobiographies, which tend to legitimate, as Bergland explains, the "dominant cultural images of the transformed American while containing the Other in preadult, childlike states" (159). Mekas transcends this pattern because he adopts New York as his home, but only in its more cosmopolitan and cultural sense, becoming part of the underground life that welcomes diversity, and escaping the dominant values of Americanization which exclude the Other. In this context, Mekas's camera work can be understood as a metaphor for the role played by Culture in the building of his new life, since the mediation of the camera leads him to a more conscious and detached gaze, creating a distance that helps him to open his viewpoint, and to search for new roots through a culture that is both "American" - cinematic, visual, industrialized —and cosmopolitan.

Mekas's involvement in New York's cultural life has its filmic correlative in his growing self-consciousness as diarist and filmmaker. In the first two reels, his visual style was restrained and unobtrusive, staying within the conventions of traditional documentary. From reel three on, the marks of his presence are more explicit, through visual style and through his commentaries in the voice-over. In these reels we begin to see the first signs of the loose camera work and rapid in-camera editing so common to his subsequent diaries. Mekas also reflects on his role as diarist, stating at the ends of reel three and of reel four that "it's my nature to record." "I have lost too much," he explains, "so now I have these bits I have passed through." This statement links his cinema with the home-movie approach, since what he redeems from definitive loss are only "bits I have passed through." At the same time, Mekas places himself in the framework of the classical Bazinian vindication of cinema as embalmer of life (11-19), though here within an autobiographical context. But this sense of loss acquires a deeper meaning because it comes from his experience as a displaced person, as someone who has left his home, his family, and half of his life far behind. Mekas needs to insist on this, beginning with the title of the film, which repeats the word "lost" three times. He also acknowledges the therapeutic practice of his shooting, as a healer of the hurts created by the loss of important things-thereby inserting himself in the broader tradition of autobiographical practices understood as narrative recovery. ${ }^{17}$ 
Visually, the urban public spaces are less prominent in reel three, but his voice-over retains the street as the dominant chronotope, reflecting the moods of wandering between loneliness and nostalgia, and the efforts to build a new life. His recollections move from a sense of novelty expressed early in reel three- "the city, the people, everything was new. We walked through the city, we submerged in it" - to his former feelings, now stated in third person: "He was very shy and very lonely during this period. He used to take long, long walks. He felt very close to the park, to the streets, to the city." The urban settings compete now with new scenes of the countryside, but by and large, New York City is still the main space-not only its streets, but also its parks, especially Central Park. Nevertheless the meaning of these public spaces is gradually changing. Mekas needs time to find himself at home in this new land, and he spends periods getting to know those places, "submerging" himself in them. In this way the space becomes almost the co-protagonist, that companion Mekas needs to know better if he is to begin again. He even establishes a dialogue with it at the end of the reel, giving voice to images of the countryside: "We were driving back to New York that day, with Bellamy. I was looking at the landscape. I knew I was in America. What am I doing here, I asked myself. There was no answer. The landscape didn't answer me." We will need to wait to reel five to find that answer.

Mekas devotes most of reel four to recording different political activities in New York. He joins demonstrators against air raid tests, a picket of the Women's Prison on 8th Street, and a march during the First International Strike for Peace. The street remains the main chronotope in this reel, but by this time Mekas has moved away from the soliloquist approach of reels one and three, and is now making space for the public life surrounding him in his new milieu. Yet Mekas is still the "watcher" of reel two, going out to the streets of New York to record it all. His reflections on this in the voice-over show a kind of impulsive need, not rationalized: "I do not know if I've understood you. ... I was just a passer-by, from somewhere else, from completely somewhere else, seeing it all, with my camera, and I recorded it, I recorded it all. I don't know why." He needs again to get to know his new place, its people, and the camera is his tool to approach them. He does not feel completely at home there, but he keeps coming back because, as he explains later on, "I wanted to feel its pulse, to feel its excitement." Mekas as autobiographical subject is struggling between the centripetal and centrifugal forces of Bakhtin's well-known metaphor that Bergland poses as distinctive trends in ethnic autobiographies (160). He needs to feel part of New York life, but his attention tends to the alternative social and political struggles of that time. 
One of those struggles, the Strike for Peace march that Mekas shows in reel four, becomes a metaphor for the changes taking place in his life. Mekas makes it explicit when he comments on the images of the people marching: "So let me continue. I don't want to look back. Not yet, or not anymore. Ahead, ahead I am pushing." Through the images and the voice-over, the street seems to incorporate a goal, a destination, fusing the spatial and the temporal dimensions. In this way, the street gets closer to a road, a symbol of the course of a life, which Bakhtin identifies as a main chronotope of the novel: "Time, as it were, fuses together with space and flows in it (forming the road); this is the source of the rich metaphorical expansion on the image of the road as a course" (244). The incorporation of a direction (the people marching) and of a goal (literally a political one) changes therefore the axiological implications of the street. Up to this point the place of the lonely wanderer, it now moves closer to a course of life, pointing out a new meaning in Mekas's struggle. As Bakhtin also points out, this street/road becomes here the space of socio-historical heterogeneity, of the collapse of social distances $(243,245)$, helping Mekas merge with his new country and share its goals, a move already seen during reels three and four but now condensed in this brief section of the Strike for Peace march toward the end of reel four.

\section{MEKAS'S NEW PARADISE: NATURE AS CHRONOTOPE}

The change experienced by Jonas Mekas finds its full expression in reels five and six, where he undergoes a kind of rebirth with a sense of stronger selfconfidence in his future. This change of mood is translated into a new, risky, experimental style that explores camera speed, light values, focus, and movement in a jazz-like fashion. The structure of these two reels is also more elaborate and less dependent on mere chronology, as for instance in the two haiku sequences of reel five. Here, Mekas displays a non-chronological structure by using very short entries of visual motifs related to nature, numbered and separated by titles. The voice-over repeating the same word three times evokes the three-verse format of the haiku. Though some of the images are not too different from ones in other parts of these last reels, their structuring and the voice-over give the haiku sequences a non-narrative, non-chronological shape that liberates the film from its home-movie look, and links it more clearly to the modes of avant-garde cinema.

Mekas's new confidence is reflected in a different chronotope during these last two reels. Now "nature" - understood spatially, associated with the countryside, with rural space- - becomes the dominant chronotope. The temporal dimension of the events portrayed in these final reels has less relevance, since 
the chronotope of nature is associated now with "paradise," a place where there is no time but eternity. This chronotope also echoes the idyllic chronotope proposed by Bakhtin in literature (224-27). For Bakhtin, in a narrative of this type, space is the main axis, articulated around familiar sites, full of details of everyday life. Time acquires a cyclic rhythm associated with folk tradition. And human life is linked to the life of nature, underlying "the unity of their rhythm, the common language used to describe phenomena of nature and the events of human life" (226). Reel five clearly mirrors this idyllic chronotope, with nature becoming a visual metaphor for this new harmony, structured in the haiku sequences with their non-chronological non-narrative form.

Different strategies clearly mark this change of chronotope. In the voiceover, Mekas talks metaphorically about the uselessness of a road in a poetic tale resembling his struggle. The story, told twice, is about a man who wanted to know what was at the end of the road, and "when later, many years later, after many years of journey he came to the end of the road, there was nothing, nothing but a pile of rabbit shit." This conclusion- "the road leads nowhere"-is not experienced as a failure, but rather as a deconstruction of a temporal understanding of personal identity in favor of a spatial understanding. Mekas does find a new identity, though one associated with a new paradise he has regained-that place of happiness lost after his departure from Lithuania. This paradise is defined visually through his communion with nature, linked inextricably to childhood and play. This change begins with his staying at Stein's house in Vermont, but is most evident in the two haiku sequences of reel five. Mekas resorts to the clear non-narrative structure to underline the experience of paradise, a space not marked by temporality, since the goal is already reached. The recreation of paradise is underlined in the "Rabbit Shit Haikus" sequence, with its repetition of the word "childhood" in four of the haiku entries, each illustrated by different visual motifs, among them Mekas's childlike behavior, playing the accordion and running through snowfields. In the "Fool's Haikus" sequence, though there is a change of location to Central Park, again we can see the playfulness of the characters, "making fools" of themselves, as Mekas says, celebrating a new happiness through the attitudes of childhood.

These themes constitute for David E. James "the summary narrative of the diary films" of Jonas Mekas, which he identifies as "the attempt to regain Lithuania," and with it the recovery of the organic village community, the rural scene, and the cultural practices appropriate to it (158). James also relates this to the "folk art" that Mekas defended in his writings as early as 1960 , as the most proper way of celebrating those values - a folk art that found its way into Mekas's work through his use of the home-movie 
approach. ${ }^{18}$ These remarks again point out the singularity of Mekas's process of Americanization, which transcends a conventional socio-political explanation, since his experience is not linked to that framework, but to a cultural one. In this sense, his process of integration is better understood as a recuperation of his dialogue with culture, though now in the United States and through the new means of his film practice.

That integration is expressed in reel six, with its emphasis on Mekas's role as filmmaker, and with its stress on his understanding of paradise as being regained through culture, and mainly through cinema. The main parts of this reel-the trip to the Flaherty Film Seminar and the visit to Stony Brookshow an intense fusion of his filmmaking practice and the playful experiencing of nature already seen in reel five. The trip with some friends-among them avant-garde filmmaker Ken Jacobs_- to the Flaherty Seminar in Vermont becomes an act of vindication of Jonas Mekas as filmmaker, while also introducing an ironic commentary on the documentary cinema establishment. Rejected by the Flaherty Seminar, Mekas and his friends stand outside as "the monks of the order of cinema," wrapped up in their sleeping blankets as a kind of monastic habit. With Gregorian music in the background, they see themselves as the true guardians of the purity of cinema. At the same time, we see Mekas (shot by Ken Jacobs) freely filming the flowers of the land as a visual celebration of that new order of cinema. Paradise has been regained, and Mekas celebrates it in his interplay with nature as seen through the lens of his Bolex camera.

The last section of the film, at Stony Brook, creates similar axes. The Gregorian chant plays again, and Mekas remembers that time as "good"—as "being in a church." The group of friends arrives in the countryside. Playfulness is the overriding mode in this new harmony with nature that becomes the dominant chronotope of this final part. But again nature and cinema merge. Using footage of himself and of Jacobs in two explicitly different parts, Mekas makes us face a very self-conscious sequence where filming parallels enjoying nature and friendship. The possible contradiction between the harmonic world of nature and the mechanical mediation of film apparatus is blurred by the amateurism of the filming, fusing them in a singular blend, challenging both the industrial and the avant-garde modes of filmmaking. Mekas is proposing a personal, autobiographical film portrait, clearly removed from industrial narrative cinema. And though he is resorting to some modes of avant-garde cinema, with its jazz-like, very self-conscious style, at the same time he is foregrounding amateurism as the dominant stylistic approach, moving away from the conceptual or political variations of the prominent avant-garde cinema of the sixties. 
The last sentences of Mekas's voice-over in the Stony Brook sequence close the film with a new reworking of the spatial understanding of his personal quest. He does not seem quite certain of having attained a final place to settle, as if then he would need to justify his current happiness to protect himself from future disillusionment: "Since no place was really his, no place was really his home, he had this habit of attaching himself immediately to any place." But the final note in any case is positive, since now he is able to create memories of his new life in the United States: "He remembered another day. Ten years ago he sat on this beach." In this way he creates a temporal tension in his inner reconstruction, though always linked to a place: "Again I have memories. . . . I have a memory of this place. . . . I have been here before. . . . I have really been here before. I have seen this water before. Yes, I have walked upon this beach, these pebbles." These new memories are not a sign of his lost paradise in Lithuania, but of his new identity in America, now possessing a sense of recovery and hope. Mekas does not present himself any more as the lonely displaced person of the first reels. He has regained a new home through culture, and from now on his film diaries will deal with that home and the friends who inhabit it. ${ }^{19}$ The final proof of that change, as Scott Macdonald points out, comes from outside of the narrative, from the completion of the film Lost, Lost, Lost (32). Some twenty years after shooting those first images, Mekas feels confident enough to face the footage of those early years, editing it to give shape to this powerful and personal chronicle of loss and recovery.

\section{CONCLUSION}

Lost, Lost, Lost provides an insightful self-portrait of the immigrant experience through film, fusing the typical contradictions suffered by first-generation immigrants with the specific challenges assumed by Jonas Mekas, after he decided first to film that experience and later on to make it a determinant force of integration into his new country. Focused on the process of acculturation, this self-portrait is unique in cinema because of Mekas's condition as first-generation immigrant, and because of his involvement with the activities of the independent and avant-garde film world, which made him feel at home thanks to the values of culture, rather than to the social or political values associated with America.

A chronotopic analysis shows how Mekas's immigrant experience is expressed in this film mainly through the spaces he inhabits. The temporal axis is less relevant because of the diary format of his filming, placing it close to the daily routines of the home-movie approach and to the cyclical time of 
the Bakhtinian idyllic chronotope. Space, however, becomes very productive for understanding the process of Mekas's acculturation in America. In the first four reels, which cover his arrival and first years in New York, the street becomes the main chronotope: a place where he feels more at ease, as a wanderer who needs to get to know the new space, and as a watcher who needs to record it all with his camera. Beginning with reel five, Mekas shows a change, a new acceptance of his new country, expressed also spatially through the chronotope of nature. This new harmony, which replaces his lost paradise of Lithuania, also includes his film activities, now merged with nature in a symbolic fusion of folk art and nature.

\section{NOTES}

AUthor's nOte: I am indebted to Prof. Rosalía Baena for her advice and support in the writing of this article.

1. This film is available at <http://www.facets.org $>$ in the US, at <http://www.moviemailonline.co.uk> in the United Kingdom, and at <http://<www.re-voir $>$ in France.

2. See mainly the section "Forms of Time and of the Chronotope in the Novel" in Bakhtin's The Dialogic Imagination (84-258). In film studies, besides Montgomery and Sobchack, Bakhtin has been used by Robert Stam in Subversive Pleasures, though he focuses on issues such as language, heteroglossia, carnival, and dialogism; and by James M. Moran, who explores the "home mode" in video and television as a chronotope in There's No Place like Home Video.

3. For a study of the relationships between documentary and avant-garde in autobiographical films, see my article "Diálogos entre el documental y la vanguardia en clave autobiográfica."

4. Besides Lane's work, two books cover related issues: Beauvais and Bouhours's collection Le Je Filme, which includes discussions of experimental films; and Renov's The Subject of Documentary, a compilation of articles including one about Lost, Lost, Lost published originally in David James's collection on Mekas, To Free the Cinema.

5. See James's chapter "Film Diary/Diary Film: Practice and Product in Walden" (To Free the Cinema 144-79). His remarks center on Mekas's Walden, but can be extended to his other diary films.

6. For a more detailed exploration of the relationship between diary films and home movies, see Odin ("Du film de famille") and Allard.

7. Egan is talking here about the work of Jim Lane and Tom Joslin.

8. Quoted from Jérôme Sans's interview of Mekas, included in Just Like a Shadow.

9. This key difference between autobiographies and diaries has been explained by Philippe Lejeune: "L'autobiographie es avant tout un récit rétrospectif et global, qui tend á la synthèse, alors que le journal intime es une écriture quasi contemporarine et morcelée, qui n'a aucune forme fixe" (L'autobiographie 24). See also his "How Do Diaries End?"

10. Reminiscences of a Journey to Lithuania stands on its own as a meditation on the past, 
since it puts together the images of his first years in the US and the images of his first trip back to Lithuania, in 1971, after twenty-five years of exile.

11. A very important trend of autobiography in cinema is related to the immigrant experience, because many filmmakers with immigrant backgrounds feel urged to revise their family past to have a better understanding of their own selves. But these filmmakers are second or third generation, trying to articulate the life narratives of their parents or grandparents into their own life experience, creating in this way what Paul John Eakin has called "proximate collaborative autobiography" (How 175-86). In these cases, as Sau-Ling C. Wong suggests, a different paradigm emerges, since they are not dealing with the opposition between Old and New World, but with a set of three systems: the "ideal" Old World values of their relatives, their "real" Old World values as actually mediated by those relatives, and the "real" New World values of the filmmakers themselves (149).

12. In the broader context of autobiographical documentaries, the temporal gap of childhood and youth is usually covered with family photographs and home movies, amplified in the soundtrack by the present comments of the filmmaker and relatives, making those parts, strictly speaking, an autobiography in collaboration.

13. Stam refers to this transfer in a brief comment on The Dialogic Imagination: "Although Bakhtin once again does not refer to cinema, his category seems ideally suited to it. . . . Bakhtin's description of the novel as the place where time 'thickens, takes on flesh, becomes artistically visible,' . . . seems in some ways more appropriate to film than to literature, for whereas literature plays itself out within a virtual, lexical space, the cinematic chronotope is quite literal, splayed out concretely across a screen with specific dimensions and unfolding in literal time" (11).

14. Mekas's written diary was published in 1991 under the title I Had Nowhere to Go. He has also published a collection of "The Movie Journal" columns that he wrote for The Village Voice, and a book of poems, There is No Ithaca.

15. I will keep the writing style of the titles, which are usually written in capital letters.

16. The myth of Ulysses is reinforced in Mekas's written work, too: first, in his written diary of these years, I Had Nowhere to Go, which finishes with a letter to an imaginary Penelope; and later on, in his poems of these years, titled significantly There is No Ithaca.

17. Several authors have studied autobiography from this point of view, including Suzette A. Henke, who explains it as pivoting "on a double entendre meant to evoke both the recovery of the past experience through narrative articulation and the psychological reintegration of a traumatically shattered subject" (xxii).

18. For Mekas's defense of the "folk art" associated with the home-movie approach, see his Movie Journal 15-16, 83.

19. One exception to Mekas's focus on his new home and friends is Reminiscences of a Journey to Lithuania, shot and edited between 1971 and 1972. This film of his visit to Lithuania again makes his immigrant condition the main issue of his film diaries, but the film's ending — in Vienna, surrounded by friends from the filmmaking communitymakes it clear that the events shown are a parenthesis in his life. 


\section{WORKS CITED}

Allard, Laurence. "Une reencontre entre film de famille et film expérimental: le cinéma personnel." Odin 113-25.

Bakhtin, Mikhail. The Dialogic Imagination: Four Essays. 1975. Austin: U of Texas P, 1981. Bazin, André. Qu'est-ce que le cinéma? Paris: Editions du Cerf, 1958.

Beauvais, Yann, and Jean-Michel Bouhours, eds. Le Je Filme. Paris: Editions du Centre Pompidou, 1995.

Bergland, Betty. "Postmodernism and the Autobiographical Subject: Reconstructing the 'Other'." Autobiography and Postmodernism. Ed. Kathleen Ashley, Leigh Gilmore, and Gerald Peters. Amherst: U of Massachusetts P, 1994. 130-66.

Boelhower, William. Autobiographical Transactions in Modernist America: The Immigrant, The Architect, The Artist, The Citizen. Verona: Del Bianco Editore, 1992.

- Immigrant Autobiography in the United States: Four Versions of the Italian American Self. Verona: Essedue, 1982.

Cuevas, Efrén. "Diálogos entre el documental y la vanguardia en clave autobiográfica." Documental y vanguardia. Ed. Casimiro Torreiro and Josetxo Cerdán. Madrid: Cátedra, 2005. 219-50.

Eakin, Paul John. "Breaking Rules: The Consequences of Self-Narration." Biography: An Interdisciplinary Quarterly 24.1 (Winter 2001): 113-27.

- How Our Lives Become Stories: Making Selves. Ithaca: Cornell UP, 1999.

Egan, Susanna. Mirror Talk: Genres of Crisis in Contemporary Autobiography. Chapel Hill: U of North Carolina P, 1999.

Fischer, Michael. "Ethnicity and the Postmodern Arts of Memory." Writing Culture: The Poetics and Politics of Ethnography. Ed. James Clifford and George E. Marcus. Berkeley: U of California P, 1986. 194-233.

Henke, Suzette A. Shattered Subjects: Trauma and Testimony in Women's Life-Writing. New York: St. Martin's, 1998.

James, David E., ed. To Free the Cinema: Jonas Mekas and the New York Underground. Princeton: Princeton UP, 1992.

Lane, Jim. The Autobiographical Documentary in America. Madison: U of Wisconsin P, 2002. Lejeune, Philippe. L'autobiographie en France. 1971. Paris: Armand Colin, 2003. . "How Do Diaries End?" Biography: An Interdisciplinary Quarterly 24.1 (Winter 2001): 99-112.

MacDonald, Scott. "Lost, Lost, Lost over Lost, Lost, Lost." Cinema Journal 25.2 (1986): 20-34.

Mekas, Jonas. "The Diary Film (A Lecture on the Reminiscences of a Journey to Lithuania)." 1972. The Avant-Garde Film: A Reader of Theory and Criticism. Ed. P. Adam Sitney, New York: Anthology Film Archives, 1987. 190-98.

—. I Had Nowhere to Go. New York: Black Thistle, 1991.

. Movie Journal: The Rise of a New American Cinema. 1959-1971. New York: Macmillan, 1972. 
There is No Ithaca. New York: Black Thistle, 1996.

Montgomery, Michael V. Carnival and Commonplaces: Bakhtin's Chronotope, Cultural Studies, and Film. New York: Peter Lang, 1993.

Moran, James M. There's No Place like Home Video. Minneapolis: U of Minnesota P, 2002.

Odin, Roger, ed. Le filme de famille: Usage privé, usage public. Paris: Meridiens Klincksieck, 1995.

"Du film de famille au journal filmé." Beauvais and Bouhours 1944-51.

Renov, Michael. The Subject of Documentary. Minneapolis: U of Minnesota P, 2004.

Rousset, Jean. Le lecteur intime. De Balzac au journal. Paris: Librairie José Corti, 1986.

Sans, Jérôme, ed. Just Like a Shadow. Paris: Patrick Remy Studio, 2000.

Sitney, P. Adam. "Autobiography in Avant-Garde Film." Millennium Film Journal 1.1 (1977-78): 60-105.

Sobchack, Vivian. "Lounge Time: Postwar Crises and the Chronotope of Film Noir." Refiguring American Film Genres: History and Theory. Ed. Nick Browne. Berkeley: U of California P, 1998. 129-70.

Stam, Robert. Subversive Pleasures: Bakbtin, Cultural Criticism, and Film. Baltimore: Johns Hopkins UP, 1989.

Turim, Maureen. "Reminiscences, Subjectivities, and Truths." James 193-212.

Villanueva, Dario. "Realidad y ficción: la paradoja de la autobiografía." Escritura autobiográfica. Ed. José R. Castillo. Madrid: Visor, 1993. 15-31.

Wong, Sau-Ling Cynthia. "Immigrant Autobiography: Some Questions of Definition and Approach." American Autobiography: Retrospect and Prospect. Ed. Paul John Eakin. Madison: University of Wisconsin P, 1991. 142-70. 